\title{
Incapacity for work in elective orthopaedic surgery: A study of occurrence and the probability of returning to work after treatment
}

\author{
Ivar Rossvoll, Pål Benum, Tobias R Bredland, Kjell Solstad, Eystein Arntzen, Stig Jørgensen
}

\begin{abstract}
Study objective-The extent to which patients undergoing elective surgery for orthopaedic disorders were incapacitated for work while they were on the waiting list and whether they were able to return to work after surgery were studied.
\end{abstract}

Design-This was a prospective cohort study of patients admitted to hospital for elective orthopaedic surgery. Main outcome measures were occurrence of sickness certification during the waiting time, and whether those incapacitated for work at the time of surgery returned to work during the first year after treatment. Multivariate logistic regression was used to estimate adjusted odds ratios for factors influencing return to work.

Setting-Orthopaedic department in charge of all elective orthopaedic surgery in a population of 197354 persons in central Norway. Subjects-All 2803 patients admitted to hospital for chronic orthopaedic disorders in the defined population between 1 September 1988 and 31 August 1990 were included in the study.

Main results-Of the 1333 patients who were employed, $42 \%$ had been certifed sick due to the orthopaedic disorder for some period of the waiting time. Sickness benefits from the national insurance scheme (paid from the 15 th day of sickness certification) had been received by $33 \%$ and were received by $29 \%$ at the time of surgery. Of 380 patients incapacitated for work at the time of surgery, $53 \%$ returned to work within the first year after surgery. Using those treated within one month of being placed on the waiting list as the reference group, the adjusted odds ratios for not returning to work during the first year after surgery were $9.2(p<0.0001)$ for those who waited more than a year for surgery, $6 \cdot 2$ $(p=0.002)$ for those waiting nine to 12 months, and $4.9(p=0.02)$ for those waiting for six to nine months.

Conclusions-A high proportion of these patients were incapacitated for work, $53 \%$ of those incapacitated returned to work within the first year after surgery. The probability of returning to work after surgery is strongly influenced by the length of time on the waiting list. Waiting for more than one year, compared with immediate treatment, was associated with an adjusted odds ratio of $\mathbf{9 \cdot 2}$ for not returning to work.

f Epidemiol Community Health 1993; 47: 388-394
There are insufficient resources for orthopaedic surgery and the waiting time for treatment is long in many parts of Norway and in several other countries. ${ }^{1-7}$ Delayed treatment probably affects patients' ability to work. Some reports indicate that for patients in need of total hip replacement delayed treatment may cause production losses, ${ }^{8}$ prolonged postoperative sick leave, ${ }^{89}$ and reduce the probability that the patient returns to work afterwards. ${ }^{289}$ We have not, however, found any reports analysing this problem in respect of patients in need of elective orthopaedic surgery in general.

Disorders of the musculoskeletal system are responsible for a large proportion of sickness certificates. In one study it was found that these disorders accounted for $25 \cdot 1 \%$ of the total number of sickness certifications ${ }^{10}$ and $35 \cdot 8 \%$ of the work days lost due to sickness. ${ }^{11}$ We suspected that a high proportion of patients waiting for orthopaedic surgery were incapacitated for work and that a long waiting time had an adverse effect on the probability that these patients would return to work after surgery.

This report aimed to study the occurrence of incapacity for work in people waiting for elective orthopaedic surgery, and the extent to which those unable to work at the time of treatment were able to return to work during the first year after surgery. Furthermore, we aimed to identify some of the factors that influence these events. In particular, we wanted to determine if a long waiting time for treatment influenced the probability of returning to work.

\section{Patients and methods} POPULATION

Our department serves all patients in need of inpatient or day patient non-acute orthopaedic surgery in 13 municipalities inhabited by 197354 persons (1.1 1990) in Sør-Trøndelag county in central Norway. These patients consume about $75 \%$ of our capacity for elective orthopaedic surgery. The population makes up $4 \cdot 66 \%$ of the total population of Norway. The proportion of people employed and the distribution of the employed among the major industries (table I) are similar in this region to those in Norway as a whole.

\section{PATIENTS}

All 2803 patients admitted to hospital for nonacute orthopaedic treatment (inpatient or day surgery) from these municipalities between 1 September 1988 and 31 August 1990 were included. Patients admitted to hospital for acute 
Table I Population *, employment and major industry groupst. Numbers for Norway as a whole are given for comparison. The number of people treated for chronic orthopaedic disorders per 1000 inhabitants/year and per 1000 employed persons are shown.

\begin{tabular}{|c|c|c|c|c|c|c|c|c|c|c|c|}
\hline \multirow[b]{2}{*}{ Inhabitants } & \multirow[b]{2}{*}{$\% E M P$} & \multicolumn{8}{|c|}{ Major industry (\% EMP) } & \multicolumn{2}{|c|}{ Treated per 1000/year } \\
\hline & & 1 & 2 & 3 & 4 & 5 & 6 & 7 & 8 & Inhabitants & $E M P$ \\
\hline $\begin{array}{l}\text { Study population } \\
\text { n=197 } 354 \\
\text { Norway }\end{array}$ & 66 & 7 & 17 & 7 & 19 & 9 & 5 & 35 & 1 & 7. & 7 \\
\hline $\mathrm{n}=4233116$ & 66 & 8 & 20 & 7 & 17 & 9 & 5 & 32 & & & \\
\hline
\end{tabular}

$\% \mathrm{EMP}=$ percentage employed of persons 16 years and over.

Major industry: 1-Agriculture, hunting, forestry and fishing; 2-oil extraction, mining, quarrying and manufacturing. Electricity, gas and water supply; 3 -construction; 4-wholesale and retail trade; restaurants and hotels; 5 -transport, storage, and communication; 6 -finance, insurance, real estate, and business services; 7-community, social, and personal services; 8-unknown.

$\star 1990,+1980$. trauma or disorders in need of acute treatment were excluded. Patients who underwent amputation, fitting or orthosis after amputation, or minor outpatient operations were not included. Details of the 2803 patients are given in table II.

Patients who met the following criteria were included in the study of return to work after surgery: in employment, aged between 18 and 65 years; treated surgically; incapacitated for work due to the disorder at the time of surgery; and received sickness benefits from the national insurance scheme (paid to all employed persons from day 15 of sickness certification).

\section{METHODS}

On the day of admission patients were interviewed about their employment and whether they had been assessed unfit for work and certified sick at some time while they were waiting for their operation. Further information was gathered from patient notes and operation protocols. The waiting time was defined as the period between being put on the waiting list and the day of admission to hospital. Before they had been placed on the waiting list all patients had been examined by one of the doctors from the orthopaedic department and had been considered to require surgery. For patients who reported that they had been certified sick, the periods of payment of sickness benefits from the national insurance scheme were noted, and it was checked that the diagnosis entered on the sickness certificate agreed with the orthopaedic disorder for which the patient was being treated. Return to work was defined as being back at work with the same working hours as before sick leave, but not necessarily within the same occupation. Information on return to work was gathered for two years after surgery for the patients treated during the first year of the study, and for one year after surgery for those treated during the second year.
STATISTICS

Data were analysed using the SPSS/PC+. The $\chi^{2}$ test was used for comparison of two independent proportions, McNemars's test was used for paired proportions. Continuity correction was used. The $\chi^{2}$ test for trends was used to test for trend across ordered groups. Pearson's correlation coefficient ( $r$ ) was used to test for association between two variables.

Multiple logistic regression analysis was used to quantify odds ratios for different factors that influenced a return to work. Categorical variables were coded as indicator variables with one category as the reference group except for the variable "type of treatment", for which deviance coding (average off all categories as reference) was used. Likelihood ratio testing was used to determine which variables were significant and should be included in the multivariate model. The significance level was set at $\mathrm{p}<0 \cdot 05$. The excluded non-significant variables did not influence noticeably the coefficients of the variables in the model. The $p$ value of different levels of categorical variables was estimated by the Wald statistic. Goodness of fit of the logistic model was tested with Hosmer-Lemeshow Ć-test, deviance and Pearson $\chi^{2}{ }^{12}$ Regression diagnostics were used to evaluate residuals. ${ }^{12}$

\section{DEFINITIONS}

Employed persons

In the present study this included all employees, self employed people, farmers, and fishermen.

\section{Sickness certification}

This is a declaration issued be a doctor to a person entitled to sickness benefits when they are temporarily unfit to work because of illness.

\section{Sickness benefits}

The National Insurance Act covers all employed persons. To obtain sickness benefits a sickness certificate must be issued by a doctor. The first three calendar days of sickness absence may, however, be declared by self certification. Sickness benefits for the first 14 days are usually paid by the employer. Self employed people and farmers receive sickness benefits for the two first weeks only when they take out supplementary insurance. From the 15 th day to one year, sickness benefits are paid by the national insurance scheme to all employed people. After one year, people who are still incapable of work are entitled to rehabilitation benefits or disability pensions. As
Table II Distribution in relation to sex, age group, treatment group, and percentage of people employed (\% EMP) in 2803 patients admitted to hospital for chronic orthopaedic disorders

\begin{tabular}{|c|c|c|c|c|c|c|c|c|c|c|c|c|c|c|c|c|c|c|c|c|}
\hline \multirow[b]{2}{*}{$\begin{array}{l}\text { Treatment } \\
\text { group }\end{array}$} & \multirow[b]{2}{*}{ No } & \multicolumn{19}{|c|}{ Age group (y) (no patients) } \\
\hline & & \multicolumn{2}{|c|}{$\begin{array}{l}-9 \\
M \quad F\end{array}$} & \multicolumn{2}{|c|}{$\begin{array}{l}10-19 \\
M \quad F\end{array}$} & \multicolumn{2}{|c|}{$\begin{array}{l}20-29 \\
M \quad F\end{array}$} & \multicolumn{2}{|c|}{$\begin{array}{l}30-39 \\
M F\end{array}$} & \multicolumn{2}{|c|}{$\begin{array}{l}40-49 \\
M \quad F\end{array}$} & \multicolumn{2}{|c|}{$50-59$} & \multicolumn{2}{|c|}{$\begin{array}{l}60-69 \\
M \quad F\end{array}$} & \multicolumn{2}{|c|}{$\begin{array}{l}70-79 \\
M \quad F\end{array}$} & \multicolumn{2}{|c|}{$\begin{array}{l}80+ \\
M F\end{array}$} & $\begin{array}{l}\% \\
\text { EMP }\end{array}$ \\
\hline 1 & 379 & & & & 1 & & 1 & 6 & 5 & 4 & 9 & 15 & 33 & 41 & 80 & 40 & 99 & 103 & 35 & 20 \\
\hline 2 & 30 & & & & & & & & & & & & 1 & & 14 & 2 & 11 & 1 & & 13 \\
\hline 3 & 521 & 1 & & 225 & 50 & 87 & 53 & 69 & 32 & 74 & 32 & 40 & 17 & 12 & 24 & 5 & 2 & 1 & & 73 \\
\hline 4 & 131 & 2 & 1 & 11 & 15 & 14 & 31 & 13 & 12 & 12 & 10 & 4 & 1 & & 4 & 1 & & & & 70 \\
\hline 5 & 460 & 221 & 18 & 214 & 49 & 243 & 30 & 25 & 22 & 17 & 66 & 8 & 56 & 16 & 57 & 2 & 23 & & 4 & 50 \\
\hline 6 & 126 & 4 & & 91 & 11 & 11 & 3 & 10 & 14 & 15 & 15 & 5 & 6 & 6 & 9 & 2 & 5 & 1 & & 59 \\
\hline 7 & 109 & & & 1 & 2 & 18 & 4 & 16 & 7 & 14 & 12 & 10 & 3 & 14 & 3 & 1 & 4 & & & 80 \\
\hline 8 & 426 & 151 & 13 & 111 & 18 & 342 & 24 & 40 & 19 & 30 & 35 & 24 & 27 & 44 & 45 & 23 & 19 & 1 & 4 & 51 \\
\hline 9 & 226 & 6 & 5 & 211 & 17 & 26 & 16 & 25 & 14 & 18 & 9 & 5 & 11 & 11 & 17 & 4 & 10 & 4 & 7 & 48 \\
\hline $\begin{array}{l}10 \\
11\end{array}$ & $\begin{array}{r}383 \\
12\end{array}$ & 131 & 18 & 335 & 51 & 252 & 28 & 27 & 19 & 12 & 16 & 19 & 21 & 14 & 37 & 20 & 16 & 8 & 6 & 35 \\
\hline Total & 2803 & & & & & & & & & & & & & & & & & & & 50 \\
\hline$\%$ EMP & & 0 & 0 & 10 & 8 & 79 & 67 & & 82 & 967 & 77 & 89 & 67 & 422 & 27 & 2 & 1 & 0 & 0 & \\
\hline$\%$ of total & group & $4 \cdot 2$ & & $12 \cdot 2$ & & $15 \cdot 3$ & & $13 \cdot 4$ & & $14 \cdot 3$ & & $10 \cdot 5$ & & $16 \cdot 0$ & & $10 \cdot 4$ & & $2 \cdot 9$ & & \\
\hline
\end{tabular}

M: male, F: female.

Treatment groups: 1-total hip arthroplasty; 2-total knee arthroplasy; 3-arthroscopy/arthroscopic surgery of the knee; 4-ligament reconstruction, capsuloplasty, and arthromoty of the knee; 5-ankle and foot surgery; 6-spine surgery; 7-shoulder surgery; 8-surgery of the hand, forearm, and elbow; 9-removal of osteosynthesis material; 10-other; 11-missing data. 
Table III Distribution in relation to sex, age group, treatment group, and percentage incapacitated for work for some period of the waiting time in 1333 employed persons treated surgically for chronic orthopaedic disorders

\begin{tabular}{|c|c|c|c|c|c|c|c|c|c|c|c|c|}
\hline \multirow[b]{2}{*}{$\begin{array}{l}\text { Treatment } \\
\text { group }\end{array}$} & \multirow[b]{2}{*}{ No } & \multirow[b]{2}{*}{$(\%)$} & \multirow[b]{2}{*}{$\begin{array}{l}\text { Age } \\
(\text { mean }(y))\end{array}$} & \multirow[b]{2}{*}{$\begin{array}{l}\text { Waiting time } \\
(\text { mean }(d))\end{array}$} & \multicolumn{6}{|c|}{ Age group (y) (no of patients) } & \multicolumn{2}{|c|}{ Incapacity for work } \\
\hline & & & & & $\begin{array}{l}16-19 \\
M F\end{array}$ & $\begin{array}{l}20-29 \\
M F\end{array}$ & $\begin{array}{l}30-39 \\
M F\end{array}$ & $\begin{array}{l}40-49 \\
M \quad F\end{array}$ & $\begin{array}{l}50-59 \\
M \quad F\end{array}$ & $\begin{array}{l}>60 \\
M \quad F\end{array}$ & $\begin{array}{l}\text { Certified } \\
(\%)\end{array}$ & $\begin{array}{l}\text { Benefits } \\
(\%)\end{array}$ \\
\hline $\begin{array}{l}1 \\
2\end{array}$ & $\begin{array}{r}66 \\
4\end{array}$ & $\begin{array}{l}(5 \cdot 0) \\
(0 \cdot 3)\end{array}$ & $\begin{array}{l}58 \\
54\end{array}$ & $\begin{array}{l}480 \\
231\end{array}$ & & & $\begin{array}{ll}1 & 2 \\
& 1\end{array}$ & 21 & $\begin{array}{lr}11 & 16 \\
& 16\end{array}$ & $\begin{array}{rr}15 & 18 \\
& 2\end{array}$ & 67 & 61 \\
\hline 3 & 379 & $(28 \cdot 4)$ & 38 & 575 & 5 & $\begin{array}{ll}75 & 33\end{array}$ & $68 \quad 26$ & $\begin{array}{ll}72 & 29\end{array}$ & 3913 & 79 & 34 & 26 \\
\hline 4 & 89 & $(6 \cdot 7)$ & 34 & 612 & 1 & 1424 & 1310 & 108 & 41 & 2 & 38 & 26 \\
\hline 5 & 220 & $(16.5)$ & 42 & 651 & 3 & 1422 & 2118 & 1554 & 839 & 415 & 27 & 22 \\
\hline 6 & 58 & $(4 \cdot 4)$ & 41 & 337 & 1 & 71 & 610 & $10 \quad 12$ & $\begin{array}{ll}4 & 2\end{array}$ & 32 & 81 & 71 \\
\hline 7 & 80 & $(6 \cdot 0)$ & 42 & 511 & & 114 & 157 & 1211 & 92 & 72 & 64 & 47 \\
\hline 8 & 215 & $(16 \cdot 1)$ & 42 & 404 & 3 & 2616 & $36 \quad 15$ & 2722 & 2019 & $17 \quad 13$ & 48 & 37 \\
\hline 9 & 107 & $(8 \cdot 0)$ & 38 & 578 & 2 & 188 & 2112 & 165 & 46 & 85 & 30 & 23 \\
\hline 10 & 115 & $(8 \cdot 6)$ & 41 & 367 & 1 & 1214 & $18 \quad 15$ & 1011 & 1112 & 7 & 50 & 41 \\
\hline \multirow{3}{*}{\multicolumn{2}{|c|}{$\begin{array}{l}\text { Total } 1333 \\
\text { Incapacity for work }\end{array}$}} & $(100)$ & 41 & 525 & 31 & 299 & 315 & 327 & 221 & 140 & 42 & 33 \\
\hline & & & Certified ( $\%)$ & & $46 \quad 39$ & 4528 & $47 \quad 32$ & 4144 & $48 \quad 45$ & 4151 & & \\
\hline & & & Benefits (\%) & & 3128 & 3021 & 3524 & 3335 & 4136 & 3646 & & \\
\hline
\end{tabular}

M: male, F: female. Certified (\%)=\% of patients reporting to have been certified sick by a doctor for the disease for some period of the waiting time. Benefits ( $\%)=\%$ of patients receiving sickness benefits from the national insurance scheme for some period of the waiting time. Waiting time=the time the patient is on the waiting list to the day of hospital admission.

Treatment groups: 1-total hip arthroplasty; 2-total knee arthroplasy; 3-arthroscopy/arthroscopic surgery of the knee; 4-ligament reconstruction, capsuloplasty, and arthrotomy of the knee; 5-ankle and foot surgery; 6-spine surgery; 7-shoulder surgery; 8-surgery of the hand, forearm, and elbow; 9-removal of osteosynthesis material;
10-other.

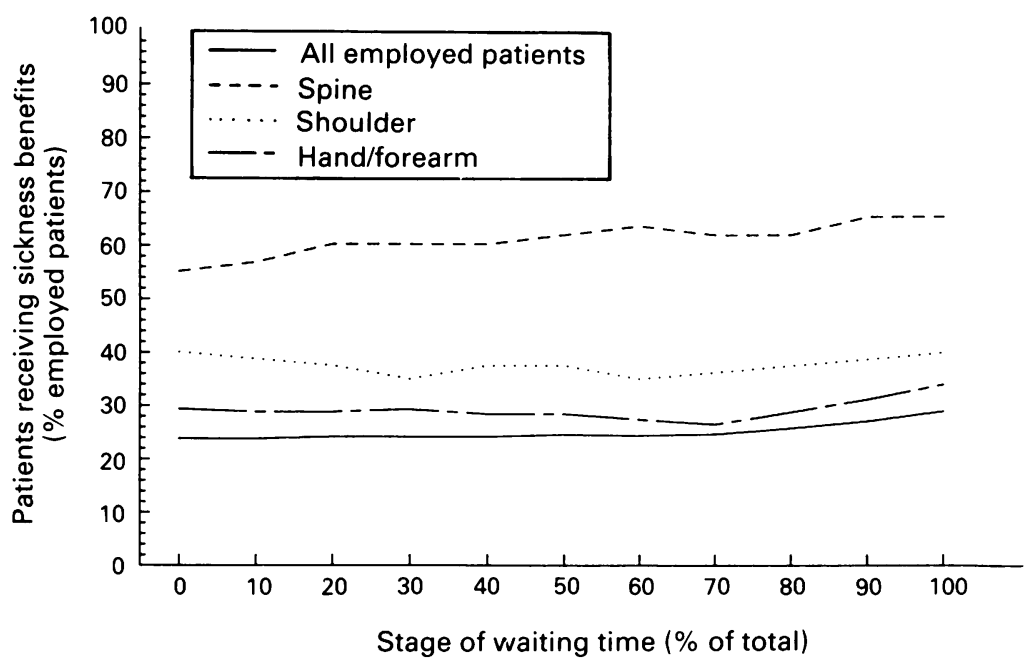

Figure 1: The percentage of 1333 employed patients incapacitated for work and receiving national insurance sickness benefits at different stages of the waiting time before surgery. Stages of waiting time are shown as a percentage of a patient's total waiting time (100\%). Patients treated for disorders of the spine, shoulder, and hand or forearm are shown.

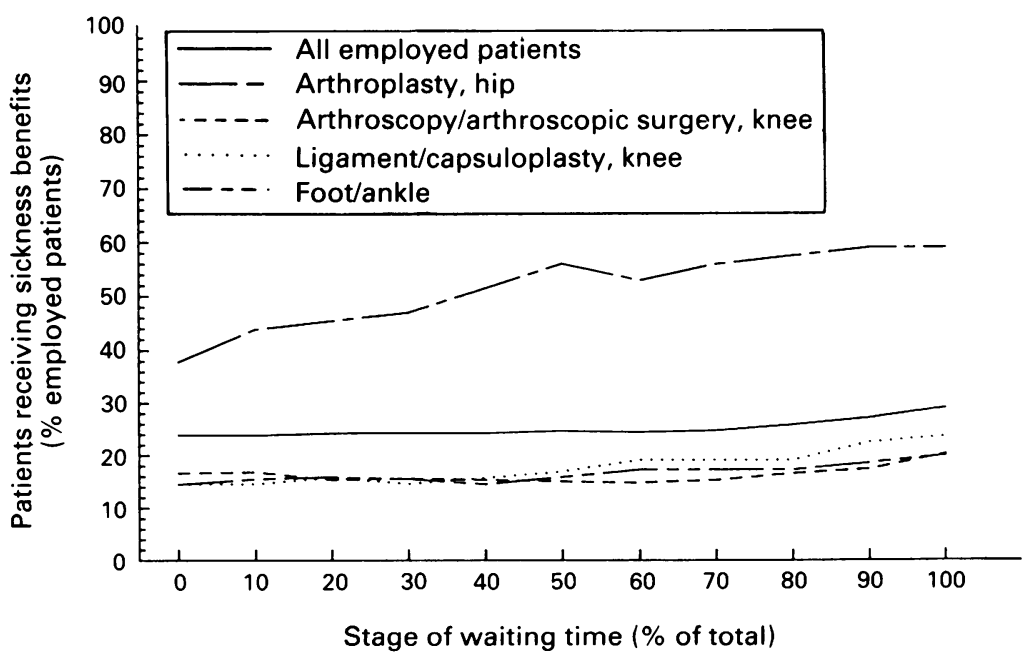

Figure 2: The percentage of 1333 employed patients incapacitated for work and receiving national insurance sickness benefits at different stages of waiting time before surgery. Stages of waiting time are shown as a percentage of a patient's total waiting time (100\%). Patients who underwent total hip prosthesis; arthroscopy or arthroscopic surgery of the knee; ligament reconstruction, capsuloplasty, or arthrotomy of the knee; and surgery to the ankle or foot are shown. sickness benefits are replaced by rehabilitation benefits after one year of incapacity for work, sickness benefits will be used for both types of benefits throughout this text.

Incapacity for work

The patient is assessed unfit for work by a doctor and a sickness certificate is issued.

\section{Results}

Twelve patients were excluded from further analysis because of insufficient data. A total of $1400(50 \%)$ of the patients were employed. The percentage of people employed was highest in patients who underwent shoulder surgery $(80 \%)$, arthroscopy/arthroscopic surgery of the knee $(73 \%)$, ligament reconstruction, capsuloplasty, and arthrotomy of the knee $(70 \%)$, and spinal surgery $(59 \%)$. The percentage of employed people among those who underwent total hip replacement was low (20\%) (table II). Of all patients treated, $1823(65 \%)$ were between 20 and 66 years old and $84 \%$ of men and $65 \%$ of women in this age group were employed.

Of the 1400 employed, 1333 were treated surgically. Details of these patients are given in table III. Of the 1333 patients, 562 (42\%) reported that they had been assessed unfit for work and had received a sickness certificate for some period of the waiting time before surgery. A total of $437(33 \cdot 2 \%)$ had received sickness benefits from the national insurance scheme because of the orthopaedic disorder during the waiting time. We found no significant difference between the proportion of employed men (252 of 734) and women (185 of 594) receiving national insurance sickness benefits in the total group. In the age group 20 to 39 years, however, the proportion receiving sickness benefits was higher in men (123 of 373) than women (53 of 237) ( $p=0.006)$.

The proportion of patients receiving sickness benefits increased significantly $(p<0.001)$ with age ( 87 of 330 employed patients 29 years old or less, 98 of 315 in the age group 30-39 years, 111 of 327 in the age group 40-49 years, 85 of 221 in the age group 50-59 years, and 56 of 140 of the patients 60 years and older). The highest proportion receiving national insurance sickness 
benefits was found among those undergoing spinal surgery ( 41 of $58(71 \%)$ ), total hip prosthesis (40 of $60(61 \%)$ ), and shoulder surgery (37 of $80(47 \%)$ ) (table III). The waiting time varied considerablymean (range) 525 (1-2012) days (SD 460 days), median 439. The percentage of employed patients receiving national insurance sickness benefits at different stages while they were waiting is shown in figures 1 and 2. There was a significant increase in the proportion incapacitated between the start (319 of $1333(24 \%))$ and the end (388 of $1333(29 \%))$ of the waiting period for the whole group $(\mathrm{p}<0.0001$, $95 \%$ CI $0 \cdot 05 \pm 1 \cdot 96 \times 0 \cdot 008$ ).

Of the 1333 patients, 380 met the inclusion criteria given for the study of return to work after surgery. Details of the 380 patients according to treatment are given in table IV. Forty two of these 380 patients were on sick leave for less than $25 \%$ of the waiting time, 42 were on sick leave for between 25 and $75 \%$, and 296 were on sick leave for more than $75 \%$ of the waiting time. A group of 59 patients had been on sick leave for more than one year at the time they were put on the waiting list. Of the 380 patients $24 \%$ returned to work within three months, $40 \%$ within six months, $50 \%$ within nine months, and $53 \%$ within 12 months of surgery (table V). There was a weak $(r=0 \cdot 15)$ but significant $(p=0.04)$ correlation between the number of preoperative waiting days and postoperative sick leave days for those who were on sick leave during the whole waiting period ( 273 patients) and then returned to work. The relation between work classified as light, moderate, or heavy and the return to work is shown in table VI. The return to work in relation to the length of time spent on the waiting list is shown in table VII. Only four of the 59 patients on sick leave for more than one year at the time they were put on the waiting list returned to work.

One year after treatment, $14 \%$ received a disability pension, $32 \%$ were still receiving sickness benefits, and $1 \%$ were students or enlisted in the army. Of the 207 patients treated during the first year, 100 did not return to work within 12 months of their operation. Only eight of these 100 returned to work during the second year of follow up. Thus, the percentage who returned to work within two years of surgery was 57 . One patient treated with spinal surgery returned during the second year while none of those who underwent total hip replacement did.

Multiple logistic regression was used in data analysis and to adjust the odds ratios for other

Table IV Preoperative data on 380 employed people incapacitated for work and certified sick due to chronic orthapaedic disorders at the time of surgery

\begin{tabular}{|c|c|c|c|c|c|c|c|c|c|c|}
\hline \multirow{2}{*}{$\begin{array}{l}\text { Treatment } \\
\text { group }\end{array}$} & \multirow[b]{2}{*}{ No } & \multirow{2}{*}{$\begin{array}{l}\text { Sex } \\
M / F\end{array}$} & \multirow{2}{*}{$\begin{array}{l}\text { Age } \\
(\text { mean }(y))\end{array}$} & \multirow{2}{*}{$\begin{array}{l}\text { Waiting time } \\
(\text { mean }(d))\end{array}$} & \multicolumn{6}{|c|}{ Length of waiting time (mth) } \\
\hline & & & & & $\overline{0-1}$ & $1-3$ & $3-6$ & $6-9$ & $9-12$ & $>12$ \\
\hline 1 & 37 & $16 / 21$ & 56 & 415 & & 3 & 7 & 4 & 4 & 19 \\
\hline 2 & 1 & $0 / 1$ & 62 & 63 & & 1 & & & & \\
\hline 3 & 76 & $54 / 22$ & 39 & 408 & 5 & 13 & 14 & 7 & 4 & 33 \\
\hline 4 & 22 & $13 / 9$ & 34 & 437 & 1 & 5 & 1 & 2 & 3 & 10 \\
\hline 5 & 41 & $17 / 24$ & 42 & 409 & 7 & 7 & 4 & 4 & 3 & 16 \\
\hline 6 & 37 & $20 / 17$ & 40 & 245 & 9 & 8 & 5 & 1 & 6 & 8 \\
\hline 7 & 34 & $20 / 14$ & 43 & 325 & 3 & 9 & 7 & 1 & 6 & 8 \\
\hline 8 & 71 & $43 / 28$ & 43 & 258 & 16 & 19 & 13 & 4 & 1 & 18 \\
\hline 9 & 20 & $14 / 6$ & 45 & 185 & 4 & 9 & 4 & & & 3 \\
\hline 10 & 41 & $21 / 20$ & 40 & 175 & 5 & 23 & 4 & 2 & 1 & 6 \\
\hline Total & 380 & $218 / 162$ & 43 & 323 & 50 & 97 & 59 & 25 & 28 & 121 \\
\hline
\end{tabular}

M: male, F: female.

Treatment groups: 1-Total hip arthroplasty; 2-total knee arthroplasy; 3 arthroscopy/arthroscopic surgery of the knee; 4-Ligament reconstruction, capsuloplasty, and arthrotomy of the knee; 5-ankle and foot surgery; 6-spinal surgery; 7-shoulder surgery; 8-surgery of the hand, forearm, and elbow 9 -removal of osteosynthesis material; 10-other.
Table $V$ Data on return to work during the first 12 months after surgery for 380 employed patients incapacitated for work at the time of surgery

\begin{tabular}{|c|c|c|c|c|c|c|c|c|}
\hline \multirow{2}{*}{$\begin{array}{l}\text { Treatment } \\
\text { group }\end{array}$} & \multirow[b]{2}{*}{ No } & \multicolumn{5}{|c|}{$\begin{array}{l}\text { No returned to } \\
\text { work by months } \\
\text { postoperatively }\end{array}$} & \multicolumn{2}{|c|}{$\begin{array}{l}\text { Days from surgery } \\
\text { to work for those } \\
\text { who returned }\end{array}$} \\
\hline & & 3 & 6 & 9 & 12 & $(\%)$ & (mean & (range)) \\
\hline 1 & 37 & - & 6 & 10 & 11 & (30) & 176 & $(112-306)$ \\
\hline 2 & & - & - & - & - & & & \\
\hline 3 & 76 & 28 & 43 & 50 & 51 & (67) & 100 & $(3-318)$ \\
\hline 4 & & 7 & 13 & 15 & 16 & & & \\
\hline 5 & 4 & 8 & 16 & 18 & 18 & $(4$ & 102 & $(17-256)$ \\
\hline 6 & 3 & 2 & 6 & 11 & 12 & & 18 & $(61-327)$ \\
\hline 7 & 3 & 12 & 17 & 19 & 19 & $(5$ & 89 & $(18-201)$ \\
\hline 8 & 7 & 24 & 31 & 41 & 43 & $(6$ & 117 & \\
\hline 9 & & 5 & 8 & 9 & 9 & $(45)$ & 99 & $(20-270)$ \\
\hline 10 & 41 & 4 & 12 & 17 & 23 & (56) & 189 & $(2-345)$ \\
\hline $\begin{array}{l}\text { Tot } \\
\%\end{array}$ & 380 & $\begin{array}{l}90 \\
24\end{array}$ & $\begin{array}{r}152 \\
40\end{array}$ & $\begin{array}{r}190 \\
50\end{array}$ & $\begin{array}{r}202 \\
53\end{array}$ & & 123 & $(2-345)$ \\
\hline
\end{tabular}

Treatment groups: 1-total hip arthroplasty; 2-total knee arthroplasy; 3-arthroscopy/arthroscopic surgery of the knee; 4-ligament reconstruction, capsuloplasty, and arthrotomy of the knee; 5-ankle and foot surgery; 6-spinal surgery; 7-shoulder of osteosynthesis material; $10-0$ ther.

variables significantly related to the outcome variable, return to work during the first year after surgery. For the 380 patients, the odds ratio for not returning to work during the first year after surgery was $9.2(p<0.0001)$ for those waiting for more than 12 months preoperatively; $6 \cdot 2$ $(p=0.002)$ for those waiting nine to 12 months; $4.9(\mathrm{p}=0.02)$ for those waiting six to nine months, $2 \cdot 0 \quad(p=0 \cdot 17)$ for those waiting three to six months, and $2 \cdot 2(\mathrm{p}=0 \cdot 09)$ for those waiting one to three months. The 50 patients treated within one month of waiting, 36 of whom returned to work,

Table VI Relation between occupation and return to work during the first year after surgery for 380 patients incapacitated for work before surgery

\begin{tabular}{|c|c|c|}
\hline \multirow[b]{2}{*}{ Occupation } & \multicolumn{2}{|c|}{$\begin{array}{l}\text { Return to work } \\
\text { during the first year } \\
\text { postoperatively }\end{array}$} \\
\hline & Yes (\%) & No (\%) \\
\hline $\begin{array}{l}\text { Light }{ }^{\star} \\
\text { Moderate } \\
\text { Heavy } \\
\text { Total } \\
\text { Total }\end{array}$ & $\begin{array}{r}69(54) \\
84(50) \\
49(57) \\
202(53)\end{array}$ & $\begin{array}{r}58(46) \\
83(50) \\
37(43) \\
178(47)\end{array}$ \\
\hline
\end{tabular}

"Light work: eg-office clerk; tmoderate work: eg-labourer in light industry; fheavy work: eg-farmer, labourer in heavy industry.

were used as the reference group (table VIII). The logistic regression model adjusted for the following: age, type of treatment, whether the patients had been on sick leave for more than one year before they were put on the waiting list, and the proportion of the waiting time for which the patients received sickness benefits. The variables coding for a previous operation for the same disorder, whether the disorder was a result of trauma, the urgency of treatment according to the doctor's evalaution, sex, occupation, and the duration of the operation were not significant in the multivariate model predicting the return to work.

Of patients 39 years or younger, 116 of a total of 162 returned to work. The odds ratios for not returning to work were 3.3 for those $40-54$ years of age $(p=0.0001)$ and 7.6 for those 55 years of age and older $(p<0.0001)$, compared with those 39 years of age or younger. Although the odds ratio for women (72 of 162 returned to work) compared with men (130 of 218 returned to work) was of univariate significance (odds ratio 
Table VII Return to work during the first 12 months after surgery in relation to length of preoperative waiting time. Numbers for all the 380 employed persons incapacitated for work at the time of surgery and for the 273 patients on sick leave during the whole waiting period before surgery are shown.

\begin{tabular}{llllllll}
\hline & \multicolumn{7}{c}{ Preoperative waiting time $(\mathrm{mth})$} \\
\cline { 2 - 7 } & $0-1$ & $1-3$ & $3-6$ & $6-9$ & $9-12$ & $>12$ \\
\hline $\begin{array}{l}\text { All 380 patients: } \\
\begin{array}{l}\text { Proportion returned } \\
\text { \% returned }\end{array}\end{array}$ & $36 / 50$ & $56 / 97$ & $35 / 59$ & $10 / 25$ & $10 / 28$ & $55 / 121$ \\
$\begin{array}{l}\text { 273 patients on sick leave during the } \\
\text { whole waiting period: }\end{array}$ & $72 \cdot 0$ & $57 \cdot 7$ & $59 \cdot 3$ & $40 \cdot 0$ & $35 \cdot 7$ & $45 \cdot 5$ \\
$\begin{array}{l}\text { Proportion returned } \\
\text { \% returned }\end{array}$ & & & & & & \\
\hline
\end{tabular}

Table VIII Multiple logistic regression analysis of factors influencing the return to work after surgery for chronic orthopaedic disorders in 380 patients incapacitated for work at the time of treatment. Odds ratios for not returning to work during the first 12 months postoperatively are shown. The first level of categorical variables is used as the reference group except for the variable "Type of treatment" where the average of the other groups is the refenence.

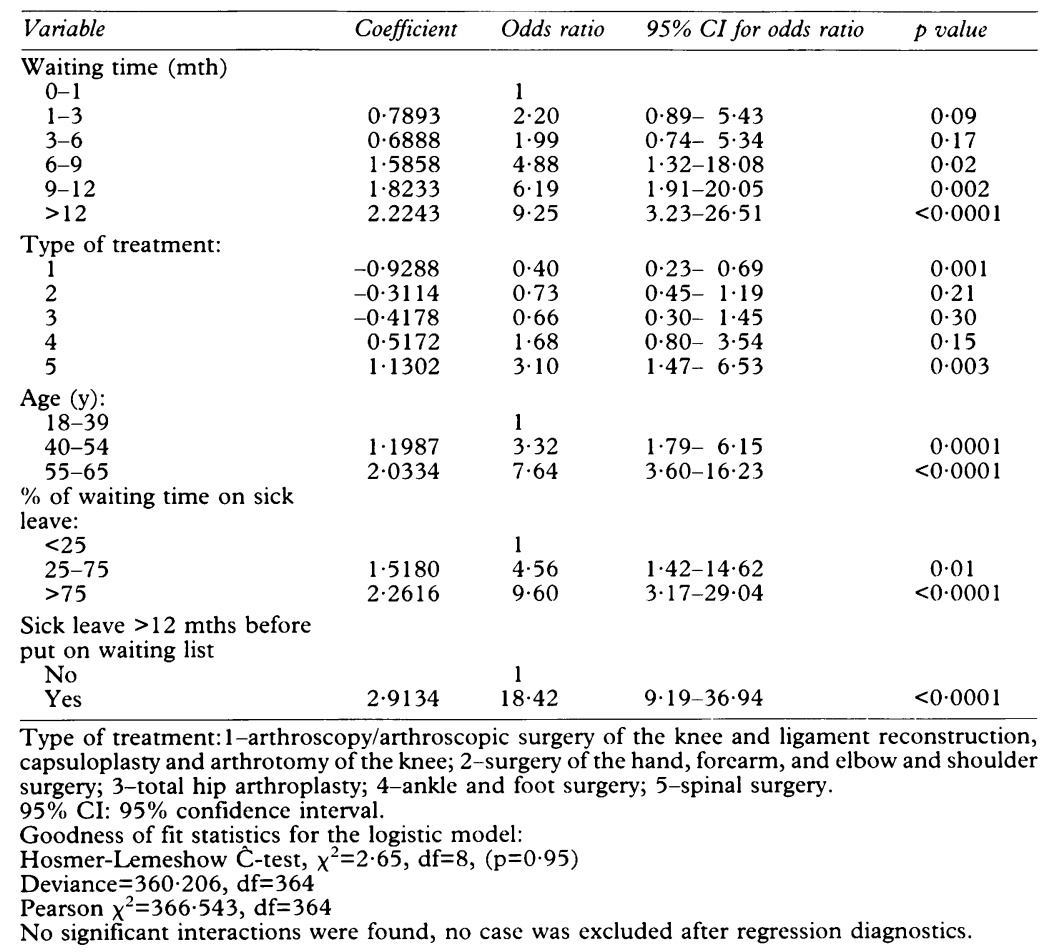

1.8, $\mathrm{p}=0.003)$, it was not significant after adjusting for the other variables in the model (odds ratio $1 \cdot 0, \mathrm{p}=0 \cdot 9$ ).

\section{Discussion}

Our findings on incapacity for work in patients in need of orthopaedic surgery are in keeping with previous studies of smaller groups of patients. Walther-Larsen et $a l^{3}$ studied the social consequences of waiting lists for orthopaedic surgery in Copenhagen. Of the 143 patients in their study, $53.1 \%$ were employed and $39 \%$ of these had been certified sick for some period of the waiting time. Jensen $e t a l^{13}$ found that 97 patients were working and 48 were on sick leave before hip replacement in 261 patients aged less than 70 years. Hede et al $^{14}$ reported that four of 22 patients who had had arthroscopy for symptoms suggestive of a lesion of a meniscus of the knee were unable to work by the time of surgery.

A high percentage $(65 \%)$ of patients treated for chronic orthopaedic disorders are in the age group 20-66 years, the productive years of working life. Of our patients in this age group, $74 \%$ were employed. For Norway as a whole the percentage employed in this age group is 78 (Central Bureau of Statistics of Norway, 1988). Thus, the percentage employed in patients waiting for orthopaedic surgery is of the same magnitude as in the population in general.

Our results showed an increase in the proportion of incapacitated patients unable to work during the waiting time. This probably reflects a natural history of worsening of the condition as time passes. It may also be due to apathy or passivity caused by being on the waiting list, as waiting for surgery may in some way legitimatise being unfit for work. Our results also show that many patients have periods of being unable to work while they are on the waiting list, as 319 were receiving national insurance sickness benefits when they were put on the list, 388 at the time of admission to hospital, and 437 patients in total had received benefits during waiting time. This indicates that 49 patients were incapacitated and unable to work for more than 14 days at some stage while they were on the waiting list but not at the time they were admitted for surgery. Thus, the influence on a person's ability to work varies over time, but the overall effect is an increase in the number of people incapacitated for work during the waiting time for surgery.

Return to work is not necessarily a good criterion of favourable outcome after surgery for individual patients because a variety of psychological, social, economic, and job related factors will influence the probability of returning to work. ${ }^{15}$ When related to all patients treated surgically in a defined population, however, return to work has significant importance. Our results indicate that a long waiting time, and thereby lengthy preoperative sick leave, seems to have a devastating effect on the probability of returning to work. In our study, a preoperative waiting time of more than six months was associated with a significantly increased risk of not returning to work within a year after surgery compared with patients treated within one month, after adjusting for other variables influencing this outcome. There was a gradual increase in this risk from six months onward. A negative effect of a long period of sick leave before surgery on the probability of returning to work after total hip replacement has previously been shown. ${ }^{289}$ Our results show that the same holds true for patients in need of orthopaedic surgery in general.

An important question in this analysis is - what factors infuenced the length of our patients' waiting time? As a consequence of insufficient capacity for treatment, a priority system favouring the patients in greatest need for surgery has been established at our department. Through a data program patients are given appointments for surgery according to a ranking list based partly on the waiting time itself and partly on an objective score calculated from parameters such as level of pain, functional deterioration, and the doctor's opinion on the urgency of surgery. This priority system was followed strictly and neither patients nor doctors could influence the waiting time (for instance, by giving shorter waiting time to patients of high social or educational level). We have no reason to believe that the waiting time was biased to give priority to patients with the highest prob- 
ability of returning to work. Thus, waiting times were influenced by the severity and urgency of the disorder, with shorter waiting times for more serious disorders. In spite of this, patients with a long preoperative waiting time had the highest risk of not returning to work, even though they were expected to have the least serious disorders. It should be noted, however, that the extremely long waiting time in some patients was due to medical or social factors that postponed surgery.

The $30 \%$ of patients who returned to work after spinal surgery may seem low compared with other studies. ${ }^{16}$ Our patients were all incapacitated for work before surgery, however, and cannot be compared directly with patients treated with low back surgery in general. In addition, our patients are not representative of spinal surgery in the general population because most patients with primary disc herniation underwent surgery in the neurosurgical department and many of these were emergency cases and therefore not included in the study.

The probability of returning to work more than 12 months after surgery seems to be low, as only eight of the 100 who had not returned to work during the first year returned during the second year of follow up. The fact that only $14 \%$ had received a permanent disability pension at the end of the first postoperate year is probably a result of the fact that this process usually takes a long time. Thus, a follow up time of 12 months seems to be sufficient to evaluate whether or not a patient will return to work after orthopaedic surgery.

The main reason for using multivariate logistic regression was to adjust the odds ratio for the main factor of interest - the length of the waiting time-for the other covariates that might influence the outcome of the return to work. The covariates associated with the highest odds ratios were sick leave for more than 12 months before being put on the waiting list and the percentage of the waiting time spent on sick leave. The 59 patients on sick leave for more than one year at the time they were put on the waiting list had a very low probability of returning to work. The main reason was probably that they had chronic disorders and an operation could only partly be expected to restore their work capacity. Patients on sick leave for more than $75 \%$ of the waiting time (296 patients) had an odds ratio of $9 \cdot 6$ for not returning to work compared with those on sick leave for less than $25 \%$ of the waiting time. The goodness of fit statistics of the multivariate logistic model show that it fits the observed data well.

Why does a long preoperative waiting time reduce the probability of returning to work? Functional deterioration, progressive decline in work motivation, increased risk that their job will be taken by another, and difficulties in finding a new job after surgery may all be explanations. ${ }^{9}$ It is also reasonable to believe that a long waiting time may reduce the possibility that surgery will achieve a good functional result.

The study population is similar to the Norwegian population as a whole. We therefore think our results are valid nationally and also for other comparable countries.

Our department is the only one that performs elective orthopaedic surgery on patients in this region, with the exception of spinal surgery, which is also undertaken at the neurosurgical department. We feel that our results for spinal surgery are representative of spinal surgery performed in an orthopaedic department, but the total number of operations on the spine in the population is considerably higher. The same is true to some extent for arthroscopic surgery of the knee, as a private clinic for sports medicine undertook 116 of these operations in patients from this population in the two year study period. A few patients are also treated in other parts of the country as a consequence of the long waiting time in our area. This number is small, however, and should not influence the results. Patients treated at our outpatient department were not included as the operations done there are minor and do not need anaesthetists or a recovery service. The primary interest of this study was the patients in need of operation on an inpatient of day patient basis.

Some studies emphasise the economic consequences of long waiting times. Hertzman et al, ${ }^{8}$ concuded that there are considerable gains in not allowing more than six months of sick leave before total hip replacement for primary arthrosis in working patients younger than 60 years old. Similar conclusions are drawn by others. ${ }^{2}$ A study based on data from our department indicates that the costs of increasing the treatment capacity for all orthopaedic patients would be quickly repaid by the resulting reduction in the payment of sickness benefits in employed patients. ${ }^{17} \mathrm{We}$ feel that our results underline further the economic consequences of long waiting lists for orthopaedic surgery. A high percentage of patients incapacitated for work due to orthopaedic disorder are "cured" and can return to work after surgery. Thus, the production losses and other costs related to lengthy sick leave while waiting for surgery are avoidable for these patients. Furthermore, our results regarding the influence of the length of the waiting time on the probability of a return to work strongly advocate surgery within a maximum of approximately six months of waiting. Partly as a result of this investigation, the capacity for elective orthopaedic surgery has been increased here and the waiting times for surgery are now declining in our region.

We conclude that a high proportion of people in need of elective orthopaedic surgery were incapacitated for work, and that $53 \%$ of those incapacitated returned to work during the first year after surgery. The probability of returning to work after surgery is, however, strongly influenced by the length of the preoperative waiting time. Waiting for more than one year, compared with immediate treatment, was associated with an adjusted odds ratio of $9 \cdot 2$ for not returning to work.

1 Porter KM. Orthopaedic audit-review of inpatient waiting lists. $B M \mathcal{F} 1985 ; 291 ; 1216-7$

2 Malchau H, Herberts P. In: Symposium New hip joints: an explosion-like development. Läkertidningen $1988 ; 85$ (38): explosion

3 Walther-Larsen S, Nielsen TG, Kisling A. Social Walther-Larsen S, Nielsen TG, Kisling A. Social
consequences of waiting lists. A questionnaire study of patients waiting for orthopaedic surgery. Ugsekr Leger 1986; patients waiting for

4 Davidge M, Vickerstaff L, Harley M, Yates J. The anatomy

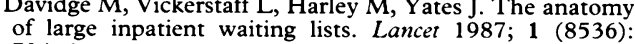
of large inpatient waiting lists. Lancet 1987; 1 (8536):
$794-6$. 5 Jorgensen

Jørgensen J, Steensen JP. Waiting lists for surgical
interventions. Ugeskr Leeger 1988; 150 (44): 2664 . interventions. Ugeskr Leeger 1988; 150 (44): 2664 Harley M. Waiting times in trauma and orthopaedic surgery.
Community Med 1988; 10 (1): 57-65. 
7 Rossvoll I, Benum P. Waiting time for treatment in hospital. How can we measure and regulate the waiting time? Tidsskr Nor Laegeforen 1991; 111: 3540-3.

8 Hertzman P, Johnsson R, Lindgren B. Cost of sick leave for total hip replacement. Acta Orthop Scand 1988; 59 (3): 266-9.

9 Johnsson R, Persson BM. Occupation after hip replacement for arthrosis. Acta Orthop Scand 1986; 57 (3): 197-200.

10 Tellnes G, Svendsen KOB, Bruusgaard D, Bjerkedal T Incidence of sickness certification. Scand f Prim Health Care 1989; 7: 111-7.

11 Tellnes G. Days Lost by Sickness Certification. Scan f Prim Health Care 1989; 7: 245-51.

12 Hosmer DW, Lemeshow S. Applied logistic regression. New York: John Wiley \& Sons, 1989
13 Jensen JS, Mathiesen B, Tvede N. Occupation capacity after hip replacement. Acta Orthop Scand 1985; 56 (2): 135-7. 14 Hede A, Hempel-Poulsen S, Jensen JS. Symptoms and level of sports activity in patients awaiting arthroscopy for of sports activity in patients awaiting arthroscopy for
meniscal lesions of the knee. F Bone foint Surg (AM) 1990; $72(4): 550-2$.

15 Cay EL, Walker DD. Psychological factors and return to work. Eur Heart f 1988; 9 (supple L): 74-81.

16 Taylor ME Return to work following back surgery: a review. Am $\mathcal{F}$ Industrial Med 1989; 16: 79-88.

17 Solstad K, Arntzen E, Jørgensen S et al. Sickness benefits and treatment. Trondheim, Norway: Norwegian Institute for Hospital Research, Working paper no $2 / 91$. 